\title{
Determination of Mortality in Cardiac Surgery: Is Cardiac Surgery Scoring (CASUS) System Effective?
}

Etik Kurul Onayı: Hastanemiz Etik Kurulu'ndan onay alınmıștır (25.05.2010). Çıkar Çatışması: Çıkar çatışması yok.

Finansal Destek: Herhangi bir kurum veya kuruluştan destek alınmamıştır.
Ethics Committee Approval: Approval was obtained from the Ethics Committee of our hospital (25.05.2010).

Conflict of Interest: There is no conflict of interest.

Funding: No support was received from any institution or organization.

Cite as: Polat S, Yurtseven N. Kardiyak cerrahide mortalite tayini: Kalp cerrahi skorlaması (CASUS) sistemi etkin mi? GKDA Derg. 2021;27(1):44-50.

öz

Amaç: Bu çalışma, kardiyak cerrahi sonrası gelişebilecek mortalite öngörüsünde kullanılan kardiyak cerrahi skorlaması (CASUS) sisteminin etkinliğini değerlendirmek ve geçerliliği test edilmiş bir yöntem olan EuroSCORE ile karşılaştırmak üzere planlandı.

Yöntem: Açık kalp cerrahisi sonrası yoğun bakım ünitesine (YBÜ) gelen ve YBÜ'de 48 saatten fazla süre kalan 18 yaşından büyük 50 hasta prospektif olarak çalışmaya alındı. Hastaların preoperatif EuroSCORE değerlendirmesi yapıldıktan sonra, postoperatif sıfırıncı günden servise alınmalarına veya yoğun bakım kalışı uzayan hastalarda postoperatif 6. güne kadar (veya olası mortalite durumuna) risk skorlaması için CASUS skorlama sistemleri kullanıldı. Her 2 modelin YBÜ mortalite tahminindeki yerini değerlendirildi.

Bulgular: Çalışma 21'i kadın, 29'u erkek, yaşları 19 ile 79 arasında değişen (ortalama 60,38 $\pm 12,50$ ) 50 hasta ile yapıldı. Olguların 5'inde (\%10) mortalite görüldü. ROC eğrisinde altta kalan alan EuroSCORE için \%45,3; CASUS 0. gün \%66,9; CASUS 1. gün \%64,7; CASUS 2. gün için \%79,8 olarak saptandı. CASUS 2. gün skorunun mortaliteyi göstermede değerli olduğu saptandı ( $p<0.01)$. Yoğun bakımda kalış günleri ile mortalite arasında istatistiksel olarak anlamlı ilişki görüldü.

Sonuç: Sonuçlarımız CASUS'un mortaliteyi tahmin etme oranının postop. 0. ve 1. günde yetersiz kaldığı, ancak postop. 2. günde yeterli olduğunu göstermektedir. EuroSCORE ise mortaliteyi tahmin etmede etkin bulunmadı. YBÜ'de kalış süresinin uzamasının mortalite riskini istatistiksel olarak anlamlı derecede artırdığı gözlendi.

Anahtar kelimeler: kardiyak cerrahi, CASUS, EurOSCORE, mortalite

ABSTRACT

Objective: This study was planned to evaluate effectiveness of cardiac surgery score (CASUS) system used for the prediction of mortality after the cardiac surgery and to compare it with EurOSCORE, a tested and approved method.

Method: Fifty patients over the age of 18 who came to the intensive care unit (ICU) after open heart surgery and stayed in the ICU for more than 48 hours were prospectively included in the study. After the preoperative EuroSCORE evaluation of the patients, CASUS scoring systems were used for risk scoring from postoperative 0 day to the service or up to the 6th postoperative day (or possible mortality) in patients whose stay in ICU was prolonged. We evaluated the place of both models in the prediction of ICU mortality.

Results: The study was conducted with 50 patients- 21 female, 29 male-, aged between 19 and 79 years (mean age: 60.38 \pm 12.50 ). Five (10\%) cases exited.The areas under the ROC curve were estimated as follows: EurOSCORE, 45.3\%; and for CASUS 0,1, and 2. day scores AUCS of ROC curve were $66,9 \%, 64,7 \%$, and $79,8 \%$, respectively. The CASUS 2 nd day score was found to be valuable in predicting mortality $(p<0.01)$. A statistically significant relationship was observed between the days of stay in the ICU and mortality.

Conclusion: Our results show that the rate of the accurate prediction of mortality of CASUS is insufficient on postop Oth and 1st day; however CASUS score on postoperative 2nd day has sufficient.predictive accuracy EuroSCORE is not found effective in the prediction of mortality. It is observed that if the duration of stay in ICU is prolonged, it statistically significantly increases the risk of mortality.

Keywords: cardiac surgery, CASUS, EuroSCORE, mortality
Received/Geliş: 05.01.2021

Accepted/Kabul: 23.02.2021

Published Online/Online yayın: 23.03.2021

Senem Polat

Bahçeșehir Üniversitesi Tıp Fakültesi Anesteziyoloji ve Reanimasyon Anabilim Dalı Istanbul - Türkiye

- senemdogancioglu@yahoo.com ORCiD: 0000-0002-8005-7642

N. Yurtseven 0000-0001-9991-2859 Sağlık Bilimleri Üniversitesi

Dr. Siyami Ersek Gögüs Kalp ve Damar Cerrahisi, Anesteziyoloji ve Reanimasyon Anabilim Dalı istanbul, Türkiye

(C) Telif hakkı Göğüs Kalp Damar Anestezi ve Yoğun Bakım Derneği'ne aittir. Logos Tıp Yayıncılık tarafindan yayınlanmaktadır Bu dergide yayınlanan bütün makaleler Creative Commons Attf-Gayri Ticari 4.0 Uluslararası Lisansı ile lisanslanmıştr. 


\section{Giriş}

Modern kardiyak cerrahide mortalite ve morbidite artışına neden olacak faktörleri öngörerek bunlara yönelik önlemler almak kaynakların doğru kullanımıyla birlikte, maliyet artışını da engelleyecektir [1]. $\mathrm{Bu}$ amaçla geliştirilmiş skorlama sistemleri ile yoğun bakımlar, kalite ve performans yönünden karşılaştırılmakta, mortalite ve morbidite objektif olarak değerlendirilebilmektedir.

Avrupa kardiyak cerrahi risk değerlendirme sistemi (European System for Cardiac Operative Risk Evaluation- EuroSCORE) güncel kardiyak cerrahide kullanılan risk modelleri içerisinde en çok kabul görmüş ve geçerliliği ortaya konmuş olanıdır. EuroSCORE sonuçlarının kardiyak cerrahi maliyetleri ile korele edilebileceği, kaynakların etkin kullanımı için yön gösterici olabileceği belirtilmiştir ${ }^{[2]}$.

Kalp Cerrahi Skorlaması (cardiacsurgeryscore-CASUS), özel bir kardiyak cerrahi skorlama sistemi olup, erken postoperatif dönemdeki patofizyolojik özelliklere göre hazırlanmıştır. Özellikle mortalite tahmini bakımından diğer modellere göre daha doğru sonuçlar verdiği belirtilmektedir ${ }^{[3-5]}$.

$\mathrm{Bu}$ çalışma, kardiyak cerrahi sonrası gelişebilecek mortalite öngörüsünde kullanılan CASUS sisteminin etkinliğini değerlendirmek ve geçerliliği test edilmiş bir yöntem olan EuroSCORE ile karşılaştırmak üzere planlandı.

\section{GEREÇ ve YÖNTEM}

Hastanemiz eğitim planlama koordinasyon kurul onayı alındıktan sonra (25.05.2010), 1 Haziran 2010-1 Haziran 2011 tarihleri arasında, açık kalp cerrahisi sonrası YBÜ'de 48 saatten fazla kalan 18 yaşından büyük 50 hastada, prospektif olarak gerçekleştirildi. Kırk sekiz saatten önce ex olan hastalar ise çalışma dışında bırakıldı. Tüm hastaların YBÜ'ye ilk yatışları dikkate alındı. Çalışmayı yürüten kişi postoperatif dönemde tüm skorların verilerini topladı. İki YBÜ çalışanı tarafından günlük olarak verileri güncellenirken, çalışma yürütücüsü kişi, bu verileri yeniden kontrol ederek oranlar arası olası tutarsızlıklar ve gözden kaçan bir verinin olmaması sağladı. Ortaya çıkan sonuç, yoğun bakım ünitesindeki beklenen mortaliteyi yansıttı. Skorlar her farklı gün için olan en kötü değerler toplanarak hesaplandı. Skorlama sisteminin maksimum türevi (Maxscore) yoğun bakımda kaldığı sürece edinilen en kötü günlük skor olarak kaydedildi. Ortalama skor, YBÜ'deki kalış süresince tüm günlük değerlerinin toplamının kalış süresine bölünmesi ile elde edildi.

Bu çalışmada, hastaların 30 günlük mortalite tahmini için postoperatif 0 . günden postoperatif 6 . güne kadar olan süre içinde (veya hastanın 6. günden önce servise alınmasına ya da 6 . günden önce mortal olduğu güne göre) risk skorlaması için CASUS, preoperatif dönem için ise EuroSCOREskorlama sistemleri kullanılıp veriler toplandı. Çalışmada son-nokta, klinik seyir değeri 30 günlük mortalite olarak tanımlandığından 30 günlük izlem tamamlandı.

\section{Kardiyak Cerrahi Skoru (CardiacSurgeryScore-CASUS)}

Kardiyak Cerrahi Skoru (CardiacSurgeryScore-CASUS) 2005'te tanımlanmış olup, 10 değişkenden oluşan, kolay, güvenilir ve spesifik olarak kalp cerrahisi geçiren hastalar için hazırlanmış bir yoğun bakım prognostik skorlama sistemidir (Tablo 1). Belli bir hasta alt grubunda ve patofizyolojik özellikler üzerine kurgulanarak hazırlanmış olması CASUS sisteminin olumlu yönlerindendir. Kardiyak cerrahi hastalarına özgün olup, yoğun bakıma geçişten hemen sonra risk saptayıcılığı ve ayırt ediciliği yüksektir. Ek sorunları olan hastalarda ve kardiyopulmonerbaypasın erken dönem etkileri altında bile olası mortalite oranlarını belirlemede oldukça güvenilir sonuçlar verdiği gösterilmiştir. Çoğu skorlama sisteminde göz ardı edilen, ancak hastaların prognozu üzerinde önemli olabilecek parametrelere yer verilmesi, CASUS'un geçerliği ve güvenilirliğini pekiştirmektedir.

\section{İstatistiksel İncelemeler}

Çalışmada elde edilen bulgular değerlendirilirken, istatistiksel analizler için NCSS (Number Cruncher Statistical System) 2007\&PASS (Power Analysis and Sample Size) 2008 Statistical Software (Utah, USA) programı kullanıldı. Çalışma verileri değerlendirilirken tanımlayıcı istatistiksel metotların (ortalama, Standart sapma, medyan, frekans) yanı sıra normal dağılım gösteren verilerin karşılaştırılmasında, Student t test; normal dağılım göstermeyen verilerin karşılaştırılmasında Mann Whitney U test kullanıldı. 
Parametreler arası ilişkilerin değerlendirilmesinde, Pearson ve Spearman' skorelasyon analizi kullanıldı. Niteliksel verilerin karşılaştırılmasında ise ki-kare test kullanıldı. Mortaliteyi üzerine etkileri değerlendirmede ise EuroSCORE ve CASUS skor için (ROC) Curve analizi uygulandı. Sonuçlar \%95'lik güven aralığında, anlamlılık $p<0.05$ düzeyinde değerlendirildi.

\section{BULGULAR}

Çalışmaya alınan hastaların 21'i (\%42) kadın, 29'u (\%58) erkektir ve yaşları 19 ile 79 arasında değişmekte olup, ortalama $60.38 \pm 12.50$ yıldır. Hastaların YBÜ'de yatış günleri 3 ile 6 arasında değişmekte olup, ortalama yatış $5.46 \pm 1.05$ gündür. Ameliyat tipi dağılımı Tablo 2'de gösterilmektedir.

EuroSCORE ve CASUS skorunun günlere göre değişimi Tablo 3'te gösterilmiştir. EuroSCORE, 1 ile 16 arasında değişmekte olup, ortalaması $6.14 \pm 3.47$ 'dir. CASUS skorunda, postop 5. gün değerleri postop 0 . ve 1., 2. ve 4. günle karşılaştırıldığında, postop 4. gün değerleri postop 2 gün ile karşılaştırıldığında istatistiksel olarak anlamlı düşük bulundu $(p<0.05)$.

Mortaliteye göre CASUS skorları değerlendirildiğinde, postop 0. gün ve postop 1. gün CASUS skorları ölçümleri arasında istatistiksel olarak anlamlı farklılık görülmezken ( $p>0.05$ ), postop 2. gün CASUS skorlarının mortal olan hastalarda $16.80 \pm 8.04$ iken, olmayanlarda $8.84 \pm 5.23$ olarak saptandı ve bu fark istatis- tiksel olarak anlamlı bulundu $(\mathrm{p}<0.05)$. Postop 3. gün, 4. gün ve 5 . günde mortalite görülen yalnızca 1 olgu olduğundan değerlendirme yapılamamıştır. Mortalite görülen olgularda EuroSCORE ortalama $5.40 \pm 1.67$ iken, mortalite görülmeyenlerde ortalama $6.22 \pm 3.62$ olarak saptandı ve bu fark anlamlı değildi ( $p>0.05)$ (Tablo 4).

CASUS skorları ile EuroSCORE değerleri arasındaki ilişki günlere göre değerlendirildiğinde, postop 1., 2., 3. ve 4. günde sırasıyla pozitif yönde (\%53), (\%40.8), (\%47.4) ve (\%54) düzeyinde istatistiksel olarak anlamI ilişki bulundu $(p<0.01)$ (Tablo 5). Postop 0. gün ve 5. gün CASUS skorları ile EuroSCORE skorları arasında istatistiksel olarak anlamlı ilişki bulunmadı ( $p>0.05$ ). Mortalite (+) olgularda; postop 0 . gün ve 1 . gün CASUS skorları ile EuroSCORE skorları arasında istatistiksel olarak anlamlı ilişki bulunmazken ( $p>0.05$ ), postop 2. günde pozitif yönde (\%97.3) düzeyinde istatistiksel olarak anlamlı ilişki bulundu $(p<0.01)$. Mortalite (-) olgularda ise, postop 1., 2., 3. ve 4. günde CASUS skorları ile EuroSCORE skorları arasında sırasıyla pozitif yönde (\%58.3), (\%47.7), (\%46.4) ve (\%53.6) düzeyinde istatistiksel olarak anlamlı ilişki bulundu $(p<0.01)$. Postop 0. gün ve 5. gün CASUS skorları ile EuroSCORE skorları arasında istatistiksel olarak anlamlı ilişki bulunmadı ( $p>0.05)$.

EuroSCORE ile CASUS 2 skorlarının değerlendirmesinde elde edilen ROC eğrisinde altta kalan alan EuroSCORE için \%45.3, CASUS 0. gün \%66.9, CASUS

\section{Tablo 1. Kardiyak Cerrahi Skoru (CASUS).}

Skor

\begin{tabular}{|c|c|c|c|c|c|c|}
\hline \multirow[b]{2}{*}{ Organ } & \multirow[b]{2}{*}{ Tanımlayıcı } & \\
\hline & & 0 & 1 & 2 & 3 & 4 \\
\hline Solunum & $\mathrm{PaO}_{2} / \mathrm{FiO}_{2} \mathrm{mmHg}$ & ekstübe & $>250$ & $151-250$ & $75-150$ & $<75$ \\
\hline \multirow{2}{*}{ Renal } & Kreatinin (mg/dL) & $<1.2$ & $1.2-2.2$ & $2.3-4.0$ & 4.1-5.5 & $>5.5$ \\
\hline & CVVH/dializ & Yok & - & - & - & Var \\
\hline Karaciğer & Bilirubin (mg/dl) & $<1.2$ & $1.2-3.5$ & $3.6-7.0$ & 7.1-14.0 & $>14.0$ \\
\hline \multirow[t]{4}{*}{ Kardiyovasküler } & $\mathrm{PAR}=\mathrm{HR} \times \mathrm{CVP} / \mathrm{MAP}$ & $<10.1$ & $10.1-15.0$ & $15.1-20.0$ & $20.1-30.0$ & $>30.0$ \\
\hline & laktik asit (mmol/l) & $<2.1$ & $2.1-4.0$ & $4.1-8.0$ & 8.1-12.0 & $>12.0$ \\
\hline & İntraaortik balon pompası & yok & - & - & - & Var \\
\hline & Ventriküler yardımcı aygıt & yok & - & - & - & Var \\
\hline Koagülasyon & Trombosit sayısı $\times 10^{3} / \mu \mathrm{L}$ & $>120$ & $81-120$ & $51-80$ & $21-50$ & $<21$ \\
\hline Santral sinir sistemi & Nörolojik durum & normal & - & konfü & sedasyon altında & difüz nöropati \\
\hline
\end{tabular}

Kısaltmalar: CVVH: sürekli venövenöz hemofiltrasyon/hemodiyaliz; CVP: santral venöz basınç; FiO ${ }_{2}$ inspiyumdaki oksijen fraksiyonu; HR: kalp hızı; MAP: ortalama arteryel kan basıncl; PAR: basınç ayarlı kalp hızı; PaO : oksijen parsiyel basıncl; S. bilirubin: serum bilirubin; S. kreatinin: serum kreatinin 


\section{Tablo 2. Operasyon tipi dağılımı.}

\begin{tabular}{lcc} 
Operasyon Tipi $(\mathbf{n}=\mathbf{5 0})$ & $\mathbf{n}$ & $\mathbf{\%}$ \\
\hline ABCG & 27 & 54,0 \\
ACBG+AAR & 1 & 2,0 \\
ACBG+AVR+MVR+TDV & 1 & 2,0 \\
ACBG+CEA & 1 & 2,0 \\
AVR & 4 & 8,0 \\
AVR+ACBG & 2 & 4,0 \\
AVR+MV & 2 & 4,0 \\
AVR+MVR+ACBG & 1 & 2,0 \\
AVR+MVR+BENTHALL & 1 & 2,0 \\
AVR+TVR & 1 & 2,0 \\
MVR & 5 & 10,0 \\
MVR+TDV & 1 & 2,0 \\
Perikardiyektomi & 2 & 4,0 \\
Transplantasyon & 1 & 2,0 \\
\hline
\end{tabular}

Tablo 3. CASUS ve EuroSCORE değerleri.

\begin{tabular}{lccc} 
& Ort & SD & p \\
\hline EuroSCORE & 6,14 & 3,47 & \\
\hline CASUS Skoru & 10,32 & 4,04 & \\
\hline Postop 0. gün & 9,83 & 5,12 & \\
Postop 1. gün & 9,54 & 5,26 & \\
Postop 2. gün & 8,94 & 5,22 & \\
Postop 3. gün & 7,89 & 5,25 & \\
Postop 4. gün & 6,78 & 5,38 & \\
Postop 5. gün & & & \\
\hline Postop 0. gün-5. gün & & & $0,001^{* *}$ \\
Postop 1. gün-5. gün & & & $0,013^{*}$ \\
Postop 0. gün-4. gün & & & $>0,05$ \\
Postop 1. gün-4. gün & & & $>0,05$ \\
Postop 2. gün-4. gün & & & $0,038^{*}$ \\
Postop 3. gün-4. gün & & & $>0,05$ \\
Postop 2. gün-5. gün & & & $0,001^{* *}$ \\
Postop 4. gün-5. gün & & & $0,002^{* *}$ \\
\hline
\end{tabular}

Tekrarlayan Ölçümlerde Varyans Analizi

${ }^{*} p<0,05, * * p<0,01$

Tablo 4. Mortaliteye göre CASUS ve EuroSCORE değerlendirilmesi.

\begin{tabular}{|c|c|c|}
\hline $\begin{array}{c}\text { Var } \\
\text { Ort } \pm S D \\
\text { (Medyan) }\end{array}$ & $\begin{array}{c}\text { Yok } \\
\text { Ort } \pm S D \\
\text { (Medyan) }\end{array}$ & $\begin{array}{c}\mathbf{P} \\
\text { değeri }\end{array}$ \\
\hline
\end{tabular}

CASUS postop 0. gün $12,60 \pm 5,41$ (15) $10,13 \pm 3,97$ (10) 0,217 CASUS postop 1. gün $\quad 13,40 \pm 8,96$ (16) $\quad 9,35 \pm 5,06$ (9) 0,285 CASUS postop 2. gün $16,80 \pm 8,04$ (19) $8,84 \pm 5,23$ (8) $0,030 *$ CASUS postop 3 . gün $5,00 \pm 0(5)$ CASUS postop 4. gün CASUS postop 5. gün $5,00 \pm 0(5) \quad 7,07 \pm 5,50(6)$ $2,00 \pm 0(2) \quad 6,91 \pm 5,40(7)$ $5,40 \pm 1,67 \quad 6,22 \pm 3,62$

0,732

\section{Tablo 5. EuroSCORE ile CASUS skorları arasındaki ilişki.}

\begin{tabular}{llcc} 
& CASUS & $\mathbf{r}$ & $\mathbf{p}$ \\
\hline Tüm olgular & Postop 0. gün & 0,324 & 0,087 \\
& Postop 1. gün & 0,530 & $0,005^{* *}$ \\
& Postop 2. gün & 0,408 & $0,035^{*}$ \\
& Postop 3. gün & 0,474 & $0,019^{*}$ \\
& Postop 4. gün & 0,540 & $0,007^{* *}$ \\
& Postop 5. gün & 0,389 & 0,072 \\
\hline \multirow{2}{*}{ Mortalite (+) } & Postop 0. gün & 0,589 & 0,205 \\
& Postop 1. gün & 0,738 & 0,155 \\
& Postop 2. gün & 0,973 & $0,005^{* *}$ \\
\hline Mortalite (-) & Postop 0. gün & 0,319 & 0,103 \\
& Postop 1. gün & 0,583 & $0,002^{* *}$ \\
& Postop 2. gün & 0,477 & $0,018^{*}$ \\
& Postop 3. gün & 0,464 & $0,005^{* *}$ \\
& Postop 4. gün & 0,536 & $0,002^{* *}$ \\
& Postop 5. gün & 0,298 & 0,078
\end{tabular}

r: Spearman's rho korelasyon katsayısı,

${ }^{*} p<0,05,{ }^{* *} p<0,01$

Tablo 6: Yoğun bakımda kalış günlerine göre mortalite değerlendirmeleri.

\begin{tabular}{lccc} 
Yoğun bakımda kalış & Var; $\mathbf{n}(\%)$ & Yok; $\mathbf{n}(\%)$ & p \\
\hline 3.gün $(n=6)$ & $4(\% 66,7)$ & $2(\% 33,3)$ & $0,001^{* *}$ \\
4.gün $(n=1)$ & 0 & $1(\% 100)$ & \\
5.gün $(n=6)$ & 0 & $6(\% 100)$ & \\
6.gün $(n=37)$ & $1(\% 2,7)$ & $36(\% 97,3)$ &
\end{tabular}

Ki kare test

${ }^{* *} p<0,01$

1. gün $\% 64.7$, CASUS 2. gün için $\% 79.8$ olarak saptandı. Diğer günlerde bir farklılık bulunmazken, CASUS 2. gün değeri EuroSCORE ile karşılaştırıldığında, istatistiksel olarak anlamlı farklılık olduğu saptandı $(p<0.03)$ (Şekil 1). Yoğun bakımda kalış günleri ile mortalite arasında istatistiksel olarak anlamlı ilişki görüldü ( $p<0.01$ ) (Tablo 6).

\section{TARTIŞMA}

Bu çalışmada, açık kalp cerrahisi geçiren hastalarda mortalite tahmini için CASUS ve EuroSCORE karşılaştırılmış, 2. gün CASUS ile yapılan tahminin, doğruluğu kabul edilmiştir.

Kalp cerrahisinde mortalite ve morbidite ile yaşam kalitesinin belirlenmesi yapılan işin başarısını göste- 


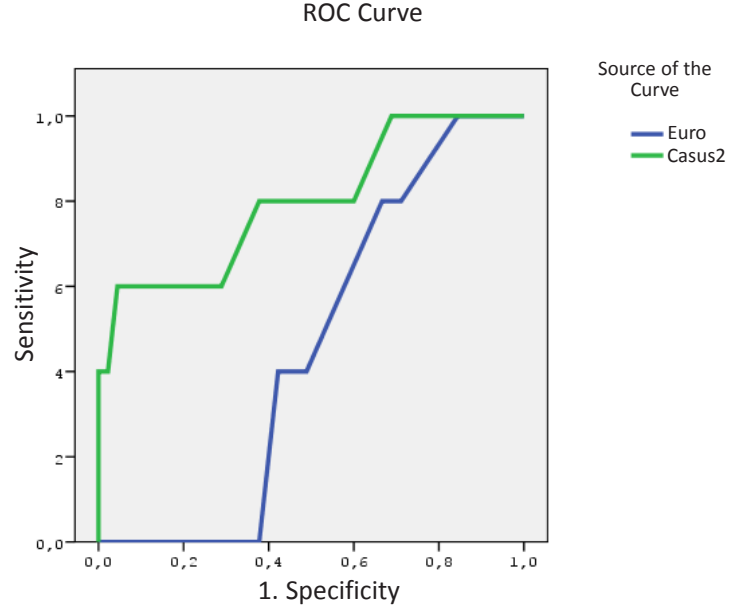

Şekil 1. EuroSCORE ile CASUS postop 2.gün ROC eğrisi.

rir. EuroSCORE basit, objektif ve çağdaş bir risk skorlama sistemidir ${ }^{[6,7]}$. EuroSCORE risk analizinde mortalite hesaplanması için saptanan parametrelerin $8^{\prime} i$ kalp dışı hasta ile ilgili faktörler, 4'ü ise kardiyak faktörlerdir. Ameliyat ile ilgili faktörler yalnızca 4'tür. Bu nedenle EuroSCORE ameliyat ile ilgili değişkenlerde, en az etkilenen bir risk skorlama metodudur.

CASUS kalp cerrahisi hastalarında kullanılan postoperatif kolay ve yalın bir skorlama sistemidir. Toplam 10 parametreden oluşan bu skorlama sistemi, ilk olarak Hekmat ve ark. ${ }^{[5]}$ tarafından geliştirilmiş olup, 3 yıl boyunca prospektif olarak 3.230 hastada incelenmiş ve sonuçları 2005 yılında yayınlanmıştır. Bu çalışmada, hastaların beklenen mortalite tahmininde geliştirdikleri skorlama sisteminin başarılı, yinelenebilir ve kolay uygulanabilir olduğunu göstermişlerdir. IABP, VAD, hemofiltrasyon gibi mekanik destek uygulamaları hastanın fizyolojik parametreleri normal olmamasına rağmen, stabil olarak yorumlanmasına neden olabilmektedir. Ancak, CASUS sisteminde bu değişkenler de mortaliteyi artıran faktörler olarak göz önünde bulundurulmuştur.

Aynı ekibin 2010 yılında yayınlanan çalışmasında, CASUS'un güvenirliliği APACHE 2 ve MODS ile karşılaştırılmış ve CASUS'un kardiyovasküler cerrahi geçiren hastalarda diğer 2 skorlama sistemine nazaran daha az sayıda ve daha spesifik parametre içerdiği ve mortalite tahmininde daha üstün olduğu gösterilmiştir ${ }^{[3,8]}$. Daha sonraki 2 ayrı çalışmada da CASUS, SOFA, APACHE II ve basitleştirilmiş akut fizyoloji skoru (simplifiedacutephysiologyscore-SAPS II) ile karşılaştırılmış ve açık kalp cerrahisi geçiren hastalarda bu 3 skorlama sistemine göre daha üstün bulunmuştur ${ }^{[8-10]}$. Doerr ve ark.'nın ${ }^{[10]}$ çalışmasında, CASUS, EuroSCORE değerleri referans alınarak diğer skorlama sistemleri ile karşılaştırılırken, EuroSCORE tahminleri ile örtüşen sonuçlar verdiği bildirilmiştir.

Raut ve ark.'nın ${ }^{[11]}$ CASUS, Lojistik EuroSCORE, APACHE II ve Yoğun Bakım Ulusal Denetim ve Araştırma Merkezi Skorunu (ICNARC) karşılaştırdıkları çalışmalarında, mortaliteyi en iyi gösteren skorlama sisteminin CASUS olduğunu bunu ICNARC, Logistic EuroSCORE ve APACHE II izlediğini belirtmişler. Exarchopoulos ve ark. ${ }^{[12]}$ ise kardiyak cerrahi geçiren hastalarda CASUS, EuroSCORE II, APACHE II, SOFA ve SAPSII skorlarını karşılaştırmışlar ve 30 günlük mortalite tahmininde CASUS skorunun AUC'nin \%89 ile en iyi skorlama sistemi olduğunu bildirmişlerdir.

Yaptığımız çalışmada, YBÜ'de en az 2 gün kalan toplam 50 hasta dâhil edildi. Mortalite oranının \%10 olarak bulunmasının nedeni, çalışmaya yüksek cerrahi risk grubundan hastaların dâhil edilmesi olarak düşünüldü. Daha önceki çalışmalarda da mortalite oranının YBÜ'de kalış süresi uzadıkça arttığı bildirilmektedir. Mortalite görülen olgularda EuroSCORE ortalama $5.40 \pm 1.67$ olarak saptanırken, mortalite görülmeyenlerde ortalama $6.22 \pm 3.62$ olarak belirlendi ve mortalite oranı için ROC eğrisi alanı EuroSCORE için \%45.3 olarak hesaplandı. Dolayısıyla bu çalışmada, EuroSCORE mortaliteyi saptamada istatistiksel olarak anlamlı bulunmadı ve mortalite tahmininde yetersiz kaldığı görüldü. Peroperatif ve postoperatif komplikasyonlar varlığında EuroSCORE'un duyarlılığının düştüğünü desteklemektedir. Yakın zamanda yapılan bazı çalışmalar da EuroSCORE sisteminde bazı değişikliklerin yapılması gerektiğini önermektedir ${ }^{[13]}$.

Mortalite ye göre CASUS skorları değerlendirildiğinde postop 0 . gün ve postop 1 . gün CASUS skorları ölçümleri arasında istatistiksel olarak anlamlı farklılık görülmezken ( $p>0.05$ ), postop 2. gün CASUS skorları arasında istatistiksel olarak anlamlı farklılık olduğu görüldü $(p<0.05)$. Mortalite görülen olgularda postop 2. gün CASUS skoru ortalaması $16.80 \pm 8.04$ olarak saptanırken, mortalite görülmeyenlerde ortalama $8.84 \pm 5.23$ olarak hesaplandı. CASUS değerlerinin 
postop. 0. gün ve 1. günde her ne kadar istatistiksel olarak anlamlı olmasa da mortalite görülen olgularda, mortalite görülmeyen olgulara göre daha yüksek seyrettiği gözlendi. Hekmat ve ark. yaptıkları tüm çalışmalarda, CASUS'un mortaliteyi tahmin etme etkinliğinin, ilk günden itibaren anlamlı olarak yüksek olduğu bildirilmişlerdir. Aynı çalışmalarda, yatış süresinin uzaması ile bu oranın arttığı gösterilmiştir. Çalışmamızda, postop. 0 ve 1 . gündeki oranların oranla düşük seyretmesi ve istatistiksel olarak anlamlı olmaması, bu skorlama sisteminin diğer kardiyak cerrahi uygulanan kliniklerde daha fazla ancak daha homojen hasta grubu üzerinde çalışılması gerektiğini göstermektedir. Çalışmamızda, postop. 2. gündeki CASUS değerleri ile mortalite tahmini arasındaki istatistiksel olarak anlamlı ilişki YBÜ'deki kalış süresinin uzamasının mortalite riskini artırdığını ve CASUS skorlama sisteminin postop 2. günde de kullanılabileceğini göstermektedir.

Çalışmamızda, hasta sayısının az olması ve CASUS'un diğer postoperatif skorlama sistemleri ile karşılaştırılmaması çalışmanın gücünü azaltmaktadır. Ancak, daha önceki 4 çalışmada, çoğunluğu aynı kişilerden oluşan ekipler tarafından yapılmış ve bu çalışmaların yalnızca 1'i farklı bir enstitüde gerçekleştirildiği için sonuçlarımızın "eksternalvalidasyon" açısından değerli olduğu ve çalışmanın gücünü artırdığını düşünmekteyiz ${ }^{[14]}$. Önceki 4 çalışma da açık kalp cerrahisi geçiren hastaları postoperatif ilk 24 saatten itibaren çalışmaya dâhil etmişlerdir ve CASUS'un mortaliteyi doğru tahmin etme oranının ilk 24 saatten itibaren diğer skorlama sistemlerine göre üstün olduğunu öne sürmüşlerdir. Kalış süresi uzadıkça risklerin ve dolayısı ile postoperatif dönemde kullanılan tüm skorlama sistemlerinin mortaliteyi doğru tahmin oranlarının birbirine yaklaştığını göstermişlerdir. Biz bu çalışmada, 48 saat ve daha uzun süre YBÜ’de yatan hastaları dâhil ederek uzun süre yatan hastalarda CASUS'un etkinliğini araştırmayı hedefledik. Sonuçlarımız CASUS'un uzun dönem yatan hastalarda mortaliteyi doğru tahmin etme oranının postop. 0 . ve 1. günde yetersiz olduğunu ancak postop. 2. günde yeterli olduğunu göstermektedir. EuroSCORE değerlerinin mortaliteyi tahmin etmede yetersiz olduğu görülmektedir.

Sonuç olarak çalışmamızda, 2. gündeki CASUS değerleri mortaliteyi doğru olarak tahmin etse de olasılıkla hasta sayısının az olması diğer günlerdeki EuroSCORE ve CASUS skorlama sistem değerlerinin istatistiksel olarak anlamsız çıkmasına neden olmuş olabilir. Geniş serili çalışmalarla bu iki skorlama sisteminin etkinliğinin karşılaştırılmasına ve CASUS skorlama sisteminin kalp cerrahisinde daha fazla kullanılması gerektiğini düşünüyoruz.

\section{KAYNAKLAR}

1. Messaoudi N, De Cocker J, Stockman B, Bossaert LL, Rodrigus IE. Prediction of prolonged length of stay in the intensive care unit after cardiac surgery: the need for a multi-institutional risk scoring system. J Card Surg. 2009;24:127-33.

https://doi.org/10.1111/j.1540-8191.2008.00716.x

2. Messaoudi N, De Cocker J, Stockman BA, Bossaert LL, Rodrigus IE. Is EuroSCORE useful in the prediction of extended intensive care unit stay after cardiac surgery? Eur J Cardiothorac Surg. 2009 Jul;36(1):35-9. https://doi.org/10.1016/j.ejcts.2009.02.007

3. Badreldin AM, Kroener A, Heldwein MB, Doerr F, Vogt $\mathrm{H}$, Ismail MM, Bossert T, Hekmat K. Prognosticvalue of daily cardiac surgery score (CASUS) and its derivatives in cardiac surgery patients. Thorac Cardiovasc Surg. 2010;58:392-7.

https://doi.org/10.1055/s-0030-1250080

4. Toumpoulis IK, Anagnostopoulos CE, DeRose JJ, Swistel DG. Does EuroSCORE predict length of stay and specific postoperative complications after coronary artery bypass grafting? Int J Cardiol. 2005;105:19-25.

5. Hekmat K, Kroener A, Stuetzer $H$, Schwinger $R H$, Kampe S, Bennink GB, Mehlhorn U. Daily assessment of organ dysfunction and survival in intensive care unit cardiac surgical patients. Ann Thorac Surg. 2005;79:1555-62. https://doi.org/10.1016/j.athoracsur.2004.10.017

6. Nilsson J, Algotsson L, Höglund P, Lührs C, Brandt J. EuroSCORE predicts intensive care units tay and costs of open heart surgery. Ann Thorac Surg. 2004;78:152834. https://doi.org/10.1016/j.athoracsur.2004.04.060

7. Nashef SAM, Roques F, Michel P, et al. European system for cardiac operative risk evaluation EuroSCORE). Eur J Cardiothorac Surg. 1999;16:9-13. https://doi.org/10.1016/S1010-7940(99)00134-7

8. Hekmat K, Doerr F, Kroener A, Heldwein M, Bossert T, Badreldin AM, Lichtenberg A. Prediction of mortality in intensive care unit cardiac surgical patients. Eur J Cardiothorac Surg. 2010 Jul;38(1):104-9. https://doi.org/10.1016/j.ejcts.2010.01.053

9. Badreldin AM, Kroener A, Heldwein MB, Doerr F, Vogt $\mathrm{H}$, Ismail MM, et al. Prognosticvalue of daily cardiacsurgery score (CASUS) and its derivatives in cardiacsurgery patients. Thorac Cardiovasc Surg. 2010;58:392-7. https://doi.org/10.1055/s-0030-1250080

10. Doerr F, Badreldin AM, Heldwein MB, Bossert T, Richter M, Lehmann T, Bayer O, Hekmat K. A comparative study of four intensive care out comeprediction models in cardiac surgery patients. J Cardiothorac Surg. 2011 Mar 1;6:21. 
11. Raut $S$, Hussain A, Ariyaratnam $P$, Ananthasayanam A, Vijayan $A$, Chaudhry $M$, Loubani $M$. Validation of Cardiac Surgery Score (CASUS) in postoperative cardiac patients. Semin Cardiothorac Vasc Anesth. 2020 Dec;24(4):304-12.

12. Exarchopoulos T, Charitidou E, Dedeilias P, Charitos C, Routsi C. Scoring systems for outcome prediction in a cardiac surgical intensive care unit: A comparative Study. Am J Crit Care 2015 Jul;24(4):327-34. https://doi.org/10.4037/ajcc2015500

13. Exarchopoulos T, Charitidou E, Dedeilias P, Charitos C,
Routsi C. Scoring systems for outcome prediction in a cardiac surgical intensive care unit: A comparative study. Am J Crit Care. 2015;24(4):327-335. https://doi.org/10.4037/ajcc2015500

14. Wilson B, Tran DTT, Dupuis JY, McDonald B. External validation and updating of the cardiac surgery score for prediction of mortality in a cardiac surgery intensive care unit. J Cardiothorac Vasc Anesth. 2019;33(11): 3028-34.

https://doi.org/10.1053/j.jvca.2019.03.066 